\title{
Searching for perfection: further progress in management of chemotherapy-induced nausea and vomiting-concluding thoughts
}

\author{
Matti Aapro ${ }^{1}$ \\ Received: 11 December 2017 / Accepted: 20 February 2018 / Published online: 19 March 2018 \\ (C) The Author(s) 2018
}

Keywords Chemotherapy-induced nausea and vomiting $\cdot$ CINV $\cdot$ Antiemetic therapy $\cdot$ NK-1 receptor antagonist 5-HT3 receptor antagonist

Significant progress has been made in the search for perfection regarding management of chemotherapy-induced nausea and vomiting (CINV) in patients with cancer. As our understanding of the physiologic aspects of this complex side effect expands, new targets and novel antiemetic therapies will continue to emerge. The substantial gains achieved with the introduction of 5-hydroxytryptamine (5-HT3) and neurokinin-1 (NK-1) receptor antagonists provide evidence that these physiologic insights can be translated into active therapies that improve patient care [1].

Strategies for CINV prevention and management will undoubtedly continue to evolve as the treatment landscape for cancer steadily advances. The demand for more effective, better tolerated cancer therapy continues to drive development of novel chemotherapeutic agents and targeted therapies. The emetogenic potential of these novel agents vary greatly, with many emerging therapies not yet classified or included in current antiemetic guidelines [2-4]. Oral chemotherapeutic agents and targeted therapies are often administered daily for extended periods of time, requiring special considerations for prevention of treatment-related nausea and vomiting [5].

The future of chemotherapy will likely include additional oral agents to ease drug administration and lower clinical costs, as well as the continued development of antibodydrug conjugates (ADCs) $[6,7]$. ADCs consist of a potent cytotoxic agent joined to a monoclonal antibody via a cleavable linker, allowing chemotherapeutic agents to be directed to

Matti Aapro

maapro@genolier.net

1 Cancer Centre, Clinique de Genolier, Case Postale (PO Box) 100, Route du Muids 3, 1272 Genolier, Switzerland tumor-specific receptors [7]. This prevents damage to normal tissues and reduces side effects, such as nausea and vomiting. This evolution in the approach to chemotherapy will potentially reduce the incidence of CINV, although traditional chemotherapy with platinum agents, anthracyclines, and alkylating agents will remain an important component of cancer therapy, particularly in the curative/adjuvant setting.

The efficacy of NK-1 receptor antagonists, coupled with the modest impact of 5-HT3 receptor antagonists to prevent delayed CINV, illustrates the need to include NK-1 receptor antagonists in antiemetic treatment regimens for patients at risk for delayed CINV [1]. The lack of head-to-head comparison trials complicates treatment selection. Each antiemetic therapy offers specific advantages and disadvantages that should be taken into consideration when selecting therapy. For example, non-oral formulations such as transdermal or extended release subcutaneous granisetron, intravenous fosaprepitant, and the new intravenous formulations of aprepitant and rolapitant represent good treatment options for patients who are unable to take or retain oral medications, including those who have difficulty swallowing, oral mucositis, or limited gut motility and/or absorption [8-11]. This reduction in pill burden can improve patient adherence to both antiemetic and anticancer treatment. In addition, netupitant/ palonosetron (NEPA) offers a convenient single capsule option for patients requiring antiemetic therapy that includes both a 5 HT3 and NK-1 receptor antagonist [12]. Rolapitant shows a different interaction with concomitant therapies, which can be an important factor for patients receiving multiple cancer therapies and supportive care measures [13]. Olanzapine can be considered an alternative option for some patients with CINV and appears to be an important agent in prevention of nausea [14].

Ultimately, no presently available antiemetic therapy alone will provide complete protection from the nausea and vomiting associated with chemotherapy across the different emetogenic phases. Ongoing trials are exploring antiemetic 
therapies in pediatric and adolescent patients, as well as those with refractory CINV, to expand the reach of currently available and novel approaches for CINV management [15]. Specific areas of unmet needs in CINV, such as nausea and anticipatory CINV, need to be addressed in future clinical research to identify the mechanisms involved in these responses and the potential strategies to overcome these extremely bothersome side effects $[16,17]$. The role for olanzapine in nausea control continues to be explored in ongoing studies of patients receiving emetogenic chemotherapy for solid tumors and hematologic malignancies [15]. Nausea should be included as a primary study endpoint in future clinical trial designs to better measure the efficacy of CINV therapies and reflect patients' true experience [16]. The control arms for ongoing clinical trials also need to include guideline-based antiemetic therapy to provide insightful comparison data that can shape future management of CINV [18].

Patient-related risk factors, including genetic differences in cytochrome P450 or 5-HT3 mutations and ethnic differences, have also been insufficiently evaluated, with emerging risk models and new suggestions for risk-adapted antiemetic therapy representing a promising pathway for better results in many situations $[19,20]$. Novel antiemetic therapies and combination approaches to overcome delayed CINV and breakthrough/refractory CINV are another focus of ongoing investigation and seek to achieve better control of nausea and vomiting after chemotherapy [21]. Effective education of the multidisciplinary healthcare team, including physicians, nurses, and pharmacists, regarding current CINV guidelines and emerging therapeutic options will likely improve the use of these regimens [1]. In addition, patients must be informed of their risk for CINV, the importance of timely reporting of symptoms, and the antiemetic therapies available for their use. By working together, patients and clinicians can continue to strive for perfection and make nausea and vomiting associated with chemotherapy a thing of the past.

Acknowledgements The author would like to thank Tristin Abair, $\mathrm{PhD}$, for her assistance in drafting the manuscript, and Trudy Grenon Stoddert, ELS, for her editorial assistance and assistance with preparing the manuscript for submission.

Financial support This educational activity is supported by grants from Merck and Co, Inc. and TESARO, Inc.

\section{Compliance with ethical standards}

Conflict of interest Dr. Aapro has disclosed that he has received consulting fees or honoraria from Amgen. He has also received payment for lectures and/or support for travel from Amgen, Helsinn, Hospira, Johnson \& Johnson, Novartis, Pierre Fabre Medicament, Roche, Sandoz, TESARO, Teva, and Vifor Pharma. Dr. Aapro has received research funding from Helsinn, Hospira, Novartis, Pierre Fabre Medicament, and Sandoz. He has also disclosed receiving fees for participation in advisory or review activities from Helsinn Healthcare, Hospira, Merck, Merck KGaA, Pierre Fabre Medicament, Sandoz, TESARO, Teva, and Vifor Pharma.
Open Access This article is distributed under the terms of the Creative Commons Attribution-NonCommercial 4.0 International License (http:// creativecommons.org/licenses/by-nc/4.0/), which permits any noncommercial use, distribution, and reproduction in any medium, provided you give appropriate credit to the original author(s) and the source, provide a link to the Creative Commons license, and indicate if changes were made.

\section{References}

1. Navari RM, Aapro M (2016) Antiemetic prophylaxis for chemotherapy-induced nausea and vomiting. N Engl J Med 374: 1356-1367

2. Roila F, Molassiotis A, Herrstedt J, participants of the MASCC/ ESMO Consensus Conference Copenhagen 2015 et al (2016) 2016 MASCC and ESMO guideline update for the prevention of chemotherapy- and radiotherapy-induced nausea and vomiting and of nausea and vomiting in advanced cancer patients. Ann Oncol 27(suppl 5):v119-v133. Available at: https://doi.org/10.1093/ annonc/mdw270

3. National Comprehensive Cancer Network NCCN clinical practice guidelines in oncology. Antiemesis Version 2.2017. Available at: www.nccn.org/professionals/physician_gls/pdf/antiemesis.pdf. Accessed 30 May 2017

4. Hesketh PJ, Kris MG, Basch E et al (2017) Antiemetics: American Society of Clinical Oncology clinical practice guideline update. J Clin Oncol 35:3240-3261

5. Costa AL, Abreu C, Pacheco TR et al (2015) Prevention of nausea and vomiting in patients undergoing oral anticancer therapies for solid tumors. Biomed Res Int 2015:309601

6. Cardoso F, Colleoni M, Di Leo A et al (2016) Oral chemotherapy in advanced breast cancer: expert perspectives on its role in clinical practice. Cancer Treat Comm 6:S1-S10

7. Nasiri H, Valedkarimi Z, Aghebati-Maleki L, Majidi J (2018) Antibody-drug conjugates: promising and efficient tools for targeted cancer therapy. J Cell Physiol 2018 Jan 10

8. Doggrell SA (2017) Granisetron in the treatment of chemotherapyinduced nausea and vomiting (CINV)-is there still a role after comparison with palonosetron? Expert Opin Pharmacother 18: $1019-1026$

9. Fosaprepitant dimeglumine [prescribing information]; Merck Sharp \& Dohme Corp: Whitehouse Station. 2017. Available at: https:// www.merck.com/product/usa/pi_circulars/e/emend_iv/emend_iv pi.pdf. Accessed: 30 May 2017

10. TESARA Announces Updates to the U.S. prescribing information for VARUBI® (rolapitant) injectable emulsion. [Press release]. Available at: ir.tesarobio.com/news-releases/news-release-details/ tesaro-announces-updates-us-prescribing-information-varubir. Accessed: 16 Jan 2018

11. Aprepitant injectable emulsion [prescribing information]. Heron Therapeutics, Inc: San Diego. 2017. Available at: https://www. accessdata.fda.gov/drugsatfda_docs/label/2017/209296s000lbl. pdf. Accessed: January 10, $201 \overline{8}$

12. Netupitant and palonosetron [prescribing information]; Helsinn Therapeutics: Iselin. 2016. Available at: https://www.akynzeo. com/assets/pdf/Prescribing_Information.pdf. Accessed: 30 May 2017

13. Rolapitant [prescribing information]; Tesaro, Inc: Waltham. 2015. Available at: https://www.accessdata.fda.gov/drugsatfda_docs/ label/2015/206500s000lbl.pdf. Accessed: 30 May 2017

14. Navari RM, Qin R, Ruddy KJ et al (2016) Olanzapine for the prevention of chemotherapy-induced nausea and vomiting. N Engl J Med 375:134-142 
15. National Institutes of Health. Clinicaltrials.gov. [Website]. Available at: clinicaltrials.gov. Accessed: 18 Jan 2018

16. Ng TL, Hutton B, Clemons M (2015) Chemotherapy-induced nausea and vomiting: time for more emphasis on nausea? Oncologist 20:576-583

17. Janelsins MC, Tejani M, Kamen C et al (2013) Current pharmacotherapy for chemotherapy-induced nausea and vomiting in cancer patients. Expert Opin Pharmacother 14:757-766

18. Ng T, Mazzarello S, Wang Z et al (2016) Choice of study endpoint significantly impacts the results of breast cancer trials evaluating chemotherapy-induced nausea and vomiting. Breast Cancer Res Treat 155:337-344
19. Grunberg SM, Slusher B, Rugo HS (2013) Emerging treatments in chemotherapy-induced nausea and vomiting. Clin Adv Hematol Oncol 11:1-18

20. Dranitsaris G, Molassiotis A, Clemons M et al (2017) The development of a prediction tool to identify cancer patients at high risk for chemotherapy-induced nausea and vomiting. Ann Oncol 28: 1260-1267

21. Einhorn LH, Rapoport B, Navari RM, Herrstedt J, Brames MJ (2017) 2016 updated MASCC/ESMO consensus recommendations: prevention of nausea and vomiting following multiple-day chemotherapy, high-dose chemotherapy, and breakthrough nausea and vomiting. Support Care Cancer 25:303-308 